\title{
Papers
}

\section{Do histopathology reports of primary cutaneous melanoma contain enough essential information?}

\author{
J M Miller, D N Slater
}

\begin{abstract}
Aims-To audit the content of primary cutaneous malignant melanoma histopathology reports with special reference to Breslow thickness and lateral excision margins.
\end{abstract}

Methods-The Trent Regional Cancer Registry was asked to provide details of primary cutaneous malignant melanomas for the most recent year available (1990). Histopathology departments were then requested to provide copies of the relevant reports, which were then analysed.

Results-In total, 178 reports were obtained from 16 departments. Breslow thickness was present in $87 \cdot 1 \%(155 / 178)$ and a comment had been made on lateral excision in $85.4 \%(152 / 178)$. A specific clearance measurement was recorded in $5 \cdot 6 \%(10 / 178)$, and in $9 \cdot 6 \%(17 / 178)$ tumour was stated to extend to the margin. In $4 \cdot 5 \%$ (8/178) neither thickness nor a comment on excision was recorded. Clinical advice on excision was offered in $12 \cdot 4 \%(22 / 178)$. A macroscopic description was absent in 6.7\% (12/178).

Conclusions-Deficiencies were identified in the quality of malignant melanoma histopathology reports in Trent Region. There is no reason to believe that significant improvements have occurred since 1990 or that other regions are performing differently. A national standard for reporting primary cutaneous malignant melanoma is recommended. As a minimum, all reports should include Breslow thickness and a specific measurement of lateral clearance. This will facilitate prognostic evaluation, clinical management and audit. This standard would not exclude the reporting of other information, depending on local policy. As with all standards, continual review must be undertaken and consideration given as to whether other more recent parameters, such as growth phase, also warrant future inclusion.

(f Clin Pathol 1996;49:202-204)

Keywords: audit, cutaneous malignant melanoma, Breslow thickness, excision margins.
To date, the content of malignant melanoma histopathology reports has largely depended upon the enthusiasm of individual pathologists, combined with the requirements of local clinicians. For well over a decade, however, there has been a widespread consensus of opinion that at least two items of information are essential to assess the prognosis and management of stage I primary cutaneous malignant melanoma. These are tumour thickness, as originally defined by Breslow, ${ }^{1}$ and information pertaining to excision margins. ${ }^{2}$ It is therefore significant that the Health of the Nation ${ }^{3}$ proposals relating to skin cancer specifically refer to the audit of tumour depth and width of excision.

During Advisory Forum discussions for Trent Region's skin cancer Health Gain Investment Programme, concern was expressed by some members that such essential information may not be routinely recorded in all malignant melanoma histopathology reports. Consequently, we decided to audit the contents of primary cutaneous malignant melanoma histopathology reports, with special reference to tumour depth and excision margins. It was hoped that the information gained would encourage further audit and, if necessary, improve the histopathological reporting of malignant melanoma. It was also envisaged that the results would serve as a baseline for the proposed Health of the Nation studies.

\section{Methods}

It was felt that an important consideration in deciding how many reports to audit would be to keep requests in even the largest department to a manageable level of no more than 40 cases. In the latest year for which complete data were available (1990), there were 268 cases, the distribution of which allowed us to keep requests to within the above limits. Accordingly, details of all of these patients were requested.

The Trent Cancer Registry was approached to provide a list of all cutaneous malignant melanoma cases registered in 1990 by hospital and with patient details. Histopathology departments that had issued the melanoma reports were then contacted to explain the aim of the audit, requesting their support and co-

Department of Public
Health, Trent Regional
Health Authority,
Sheffield
J M Miller
Department of
Histopathology,
Rotherham Hospital
Trust, Rotherham
D N Slater
Correspondence to:
Dr J M Miller,
Department of Public
Health, Rotherham Health
Authorities, 220 Badsley
Moor Lane, Rotherham S65
2QL.
Accepted for publication
21 November 1995


Table 1 Distribution of lesion thickness

\begin{tabular}{lll}
\hline $\begin{array}{l}\text { Thickness } \\
(\mathrm{mm})\end{array}$ & $\begin{array}{l}\text { Number of } \\
\text { reports }\end{array}$ & $\begin{array}{l}\text { Percentage of total } \\
\text { reports }(n=155)\end{array}$ \\
\hline $0 \cdot 1-0 \cdot 9$ & 53 & $34 \cdot 2$ \\
$1-1 \cdot 9$ & 36 & $23 \cdot 2$ \\
$2-2 \cdot 9$ & 20 & $12 \cdot 9$ \\
$3-3 \cdot 9$ & 10 & $6 \cdot 4$ \\
$4-4 \cdot 9$ & 8 & $5 \cdot 2$ \\
$5-5 \cdot 9$ & 12 & $7 \cdot 7$ \\
$6-6 \cdot 9$ & 3 & $1 \cdot 9$ \\
$7-7 \cdot 9$ & 4 & $2 \cdot 5$ \\
$8-8 \cdot 9$ & 0 & 0 \\
$9-9 \cdot 9$ & 0 & 0 \\
$10+$ & 9 & $5 \cdot 8$ \\
\hline
\end{tabular}

operation. Two weeks later, a list of locally diagnosed cases was sent to a lead consultant histopathologist in each department, requesting that they forward a copy of the relevant reports. A reminder letter was sent to those not replying after one month. The returned reports were then manually searched by one of the authors (DNS), entering data on a prepared record sheet.

Details recorded included: (1) whether there was a clear definitive diagnosis of primary cutaneous malignant melanoma; (2) whether there was a macroscopic description of the surgical specimen; (3) whether tumour thickness had been recorded and if so, its depth in millimetres; (4) whether a comment had been made on lateral excision and if so, was a specific lateral clearance measurement stated; and (5) whether clinical advice had been offered with regard to adequacy of excision or further management.
The completed forms were checked independently (JM) before data entry. After entry, the data set was verified on screen by one of the authors (JM) and a research assistant. Analysis was performed using EPI-INFO, a public domain software package for epidemiology and disease surveillance.

Ethical approval was not sought as it was planned that only aggregated patient data would be provided in the final report.

\section{Results}

In total, 268 cases were on record in the Trent Cancer Registry for 1990. The registered patients originated from 27 hospitals and the reports had been issued by 17 histopathology departments. Copy reports were requested from all departments and replies were received from 16; 230 copy reports were received.

Forty one cases were excluded as they comprised a mixture of metastatic cutaneous melanomas, non-cutaneous melanomas, wider excision specimens, benign melanocytic naevi, and a small number of unrelated conditions. In total, there were 189 reports of primary cutaneous malignant melanoma and all contained a clear definitive diagnosis. Eleven of these were in situ melanoma and were excluded from further analysis. The following percentage figures refer to the remaining 178 reports.

MACROSCOPIC DESCRIPTION

This was absent in $6.7 \%(12 / 178)$ of reports.

\begin{tabular}{lllll} 
Table 2 & Completeness of reporting of lesion thickness \\
\hline \multicolumn{7}{l}{$\begin{array}{l}\text { Number of } \\
\text { Histopathology }\end{array}$} & $\begin{array}{l}\text { Percentage of } \\
\text { reports with }\end{array}$ & $\begin{array}{l}\text { Number of } \\
\text { information } \\
\text { repartment }\end{array}$ & $\begin{array}{l}\text { information } \\
\text { present }\end{array}$ & $\begin{array}{l}\text { Percentage of } \\
\text { information } \\
\text { missing }\end{array}$ & $\begin{array}{l}\text { reports with } \\
\text { information } \\
\text { missing }\end{array}$ \\
\hline A & 10 & $90 \cdot 9$ & 1 & $9 \cdot 1$ \\
B & 10 & $90 \cdot 9$ & 1 & $9 \cdot 1$ \\
C & 27 & $79 \cdot 4$ & 7 & $20 \cdot 6$ \\
D & 1 & 100 & 0 & 0 \\
E & 5 & $71 \cdot 4$ & 2 & $28 \cdot 6$ \\
F & 1 & 100 & 0 & 0 \\
G & 3 & 100 & 0 & 0 \\
H & 4 & 100 & 0 & 5 \\
I & 19 & 95 & 1 & 35 \\
J & 13 & 65 & 7 & 0 \\
K & 9 & 100 & 0 & 0 \\
L & 1 & 50 & 1 & 5 \\
M & 18 & 100 & 0 & 0 \\
N & 19 & 95 & 1 & $11 \cdot 8$ \\
O & 0 & 0 & 0 & \\
P & 15 & $88 \cdot 2$ & 2 &
\end{tabular}

Table 3 Completeness of reporting of excision margins

\begin{tabular}{lcclc}
\hline & $\begin{array}{l}\text { Number of } \\
\text { reports with } \\
\text { comment } \\
\text { prestopathology }\end{array}$ & $\begin{array}{l}\text { Percentage of } \\
\text { reports with } \\
\text { comment } \\
\text { present }\end{array}$ & $\begin{array}{l}\text { Number of } \\
\text { reports with } \\
\text { comment } \\
\text { missing }\end{array}$ & $\begin{array}{l}\text { Percentage of } \\
\text { reports with } \\
\text { comment } \\
\text { missing }\end{array}$ \\
\hline A & 9 & $81 \cdot 8$ & 2 & $18 \cdot 2$ \\
B & 7 & $63 \cdot 6$ & 2 & $36 \cdot 4$ \\
C & 25 & $73 \cdot 5$ & 9 & $26 \cdot 5$ \\
D & 0 & 0 & 1 & 100 \\
E & 6 & $85 \cdot 7$ & 1 & $14 \cdot 3$ \\
F & 0 & 0 & 1 & 100 \\
G & 3 & 100 & 0 & 0 \\
H & 4 & 100 & 0 & 0 \\
I & 20 & 100 & 0 & 15 \\
J & 17 & 85 & 3 & 0 \\
K & 9 & 100 & 0 & $11 \cdot 1$ \\
L & 2 & $88 \cdot 9$ & 0 & 10 \\
M & 16 & 90 & 2 & 0 \\
N & 18 & 0 & 2 & 6 \\
O & 0 & 94 & 0 & 0 \\
P & 16 & & 1 & \\
\hline
\end{tabular}

\section{TUMOUR THICKNESS}

This was recorded in $87.1 \%(155 / 178)(95 \%$ confidence limits (Cl) $82 \cdot 2-92 \cdot 0 \%$ ) of reports. Table 1 illustrates the distribution of tumour thickness. Table 2 illustrates the completeness of reporting for the histopathology departments. Department O participated in the audit. No reports, however, for reasons already explained, were suitable for inclusion in the actual analysis of invasive malignant melanoma.

\section{EXCISION MARGINS}

A comment on lateral excision was present in $85 \cdot 4 \%(152 / 178)(95 \% \mathrm{Cl} 77 \cdot 4-93 \cdot 2 \%)$ of reports. An actual measurement was recorded in $5.6 \%(10 / 178)$, and in $9.6 \%(17 / 178)$ a measurement was not applicable as the tumour was stated to extend to the lateral resection margin. Table 3 illustrates the completeness of reporting for individual histopathology departments.

In $4.5 \%(8 / 178)$ of reports, there was no comment on either tumour thickness or excision margins.

A clinical comment on adequacy of excision or advice relating to further management was present in $12.4 \%(22 / 178)$ of reports. 
Discussion

Over $85 \%$ of reports recorded details of tumour thickness or excision margins, or both, but there still seems to be some room for improved reporting. Incomplete reports were noted from most departments, as illustrated in table 2 .

It is accepted that omitted information relating to tumour thickness and excision margins may have been conveyed to a clinician by verbal discussion or other means. The absence of a formal record in the report, however, is still not ideal and may create problems at a later date.

With only the occasional dissenting voice, ${ }^{4}$ tumour thickness, as defined by Breslow, is widely regarded as the most important predictive factor in primary cutaneous malignant melanoma. This fact emphasises its clinical importance and the requirement for it to be included in all histopathology reports. For example, Breslow thickness has been shown to correlate with most aspects of tumour behaviour, including patient survival rate, time to recurrence and risk of metastasis. ${ }^{5}$ In general, Breslow thickness is the key parameter that is used to decide the necessary extent of lateral clearance. ${ }^{2}$ In addition, monitoring changes in mean Breslow thickness will be a vital means of evaluating any early detection campaigns, designed to aid secondary prevention of malignant melanoma. Differing views still exist on what constitutes adequate lateral excision of malignant melanoma. ${ }^{247}$ The fact remains, however, that to plan appropriate management, irrespective of actual local policy, information relating to lateral excision is still necessary. Again, the problem was identified in most departments (table 3 ). Varying ways of conveying information identified by this audit included an actual measurement of lateral clearance, general comments on completeness or adequacy of excision and clinical advice. A specific measurement of lateral clearance in millimetres would seem to be the most desirable for two reasons. First, it accurately records detail that will have been central to making a clinical management decision. Second, such comparable data will be necessary in any audit of width of excision. Use of the terms "excision is complete" and "excision is adequate" is potentially confusing. The former tends to imply an absence of tumour at the excision margin, whereas the latter suggests that no further local treatment is necessary. Stating a specific measurement would avoid the need to use such terms and avoid ambiguity. It is suggested that a decision as to whether or not clinical advice is provided in a histopathology report is best left to local custom and practice. The absence of a macroscopic report is poor histopathological practice and at times could hinder the assessment of excision adequacy.

Support for a more standardised approach to reporting has also been provided by a National Institutes of Health (Bethesda) Consensus Conference. This commented that all cutaneous malignant melanoma reports should contain details of measured thickness and margin. ${ }^{8}$ Additional information, such as growth phase, histological subtype, Clark level, ulceration, regression and angiolymphatic invasion, was recommended as suitable for inclusion but not regarded as essential.

Ideally, we would have liked to look at cases more recent than 1990. The desirability of inclusion, however, of Breslow thickness and excision margin had become firmly established by that time and accordingly considered appropriate for auditing in the 1990 reports. There is no reason to believe that there has been a significant alteration in reporting practice since 1990 or that other regions are performing differently. The absence of such essential parameters as Breslow thickness and excision margins in $12.9(23 / 178)$ and $14.6 \%$ (26/178) of cases, respectively, clearly leaves room for improvement.

All participating hospitals have been provided with the amalgamated results and, if so wished, their own data. The Trent Region Health Gain Investment Programme has also suggested that histopathology laboratories should audit their reporting. ${ }^{9}$ Accepting that, in Trent Region, improvements can be made in the reporting of primary cutaneous malignant melanoma, several histopathology departments have already stated their intention to re-audit the subject after a 12 month period.

In conclusion, details of Breslow thickness and excision margins should be included in all reports of primary cutaneous malignant melanoma and we recommend that this constitutes the current standard for audit purposes. Other information in reports, depending on local requirements, can also be useful and histopathologists may also wish to audit these. Furthermore, as with all standards, continual review must be undertaken and consideration given as to whether more recent parameters, such as growth phase, warrant inclusion.

We are grateful to the following consultant histopathologists in Trent Region for their help and co-operation in this study: Professor Underwood and Drs Beck, Bouch, Boyd, Clark, Coup, Finbow, Gray, Goepel, Heaton, Hulman, Jenkins, KerCoup, Finbow, Gray, Goepel, Heaton,

1 Breslow A. Thickness, cross-sectioned areas, and depth of invasion in the prognosis of cutaneous melanoma. Ann invasion in the progn

2 Rampen FHJ. At least 1 centimetre for each millimetre. $B M \mathcal{F}$ 1984;289:782-3.

3 NHS Management Executive. The Health of the Nation. First Steps for the NHS. London: NHS Management Executive, 1992:16.

4 Green MS, Ackerman AB. Thickness is not an accurate gauge of prognosis of primary cutaneous melanoma. Am Dermatopathol 1993;15:461-73.

5 Delaunay MM. Prognostic factors in melanoma. In: Kirkham N, Cotton DWK, Lallemand RC, White JE, Rosin RD, eds. Diagnosis and management of melanoma in clinical practice. London: Springer-Verlag, 1992:97-112.

6 Melia J, Ellman R, Chamberlain J. Meeting the Health of the Nation target for skin cancer: problems with tackling the Nation target for skin cancer: problems with tackling prevention and

7 Timmons MJ. Malignant melanoma excision margins: making a choice. Lancet 1992;340:1393-5.

$8 \mathrm{NIH}$ Consensus Conference. Diagnosis and treatment of early melanoma. $¥ A M A$ 1992;268:1314-19.

9 Miller J, Irving F, MacLeod C. Health Gain Investment Programme Technical Review Document - Skin cancers Sheffield: Trent Regional Health Authority, (in press). 